\title{
Reynolds Number Scaling Effects on the European High-Lift Project Configurations
}

\author{
R. Rudnik* \\ DLR, German Aerospace Center, 38108 Brunswick, Germany \\ and \\ E. Germain $\ddagger$ \\ European Transonic Wind Tunnel, D-51147 Cologne, Germany
}

\section{DOI: $\underline{10.2514 / 1.36487}$}

\begin{abstract}
Within the European High-Lift projects I and II, extensive experimental and numerical investigations on the aerodynamics of high-lift configurations have been carried out. The studies are conducted using the KH3Y windtunnel model DLR F11, which is representative of a wide-body commercial aircraft. A step-by-step complexity increase up to a complete high-lift configuration, including pylon, nacelle, and nacelle strake, is carried out to identify and separate the lift and drag behavior for the components of the high-lift system and their Reynolds number dependency. The wind-tunnel data have been gathered in the European Transonic Wind Tunnel in Cologne in three different test campaigns. To include the complete analysis of the stall behavior for the different configurations of a complex three-dimensional tapered high-lift wing with nacelles extends the scope of a single paper. Therefore, the focus of the present contribution is laid on the detailed analysis of Reynolds number scaling effects with respect to lift curves and drag polars. The combined variation of the dynamic pressure and the total temperature in the European Transonic Wind Tunnel allows covering a Reynolds number range from $R e \sim 1.5 \times 10^{6}$ up to deep cryogenic conditions with $R e \sim 25 \times 10^{6}$. The final comparison of the four configurations reveals that the sequence of maximum lift values is maintained for the lowest and highest Reynolds number, although the increments between the configurations differ. The strongest increase in maximum lift is observed up to $R e \sim 5 \times 10^{6}$. In the intermediate range, $5 \times 10^{6}<R e<15 \times 10^{6}$, a highly nonlinear behavior of the maximum-lift values is observed, which requires further investigation.
\end{abstract}

\section{Nomenclature}

$\begin{array}{ll}A & =\text { reference area } \\ C_{L} & =\text { total lift coefficient } \\ C_{D} & =\text { total drag coefficient } \\ C_{p} & =\text { pressure coefficient } \\ c & =\text { model chord length } \\ c_{\text {ref }} & =\text { mean aerodynamic chord } \\ g & =\text { gap } \\ l & =\text { length } \\ M & =\text { Mach number } \\ p & =\text { static pressure } \\ q & =\text { dynamic pressure } \\ o & =\text { overlap } \\ R e & =\text { Reynolds number based on } c_{\text {ref }} \\ s & =\text { model half-span } \\ T & =\text { temperature } \\ \alpha & =\text { angle of attack } \\ \delta_{f} & =\text { flap deflection angle } \\ \delta_{s} & =\text { slat deflection angle } \\ \Lambda & =\text { aspect ratio } \\ \lambda & =\text { taper ratio }\end{array}$

Subscripts

$F \quad=$ Fuselage

Presented as Paper 752 at the 45th Aerospace Sciences Meeting and Exhibit, Reno, Nevada, 8-11 January 2007; received 5 January 2008; revision received 24 October 2008; accepted for publication 24 October 2008. Copyright (C) 2009 by Ralf Rudnik. Published by the American Institute of Aeronautics and Astronautics, Inc., with permission. Copies of this paper may be made for personal or internal use, on condition that the copier pay the $\$ 10.00$ per-copy fee to the Copyright Clearance Center, Inc., 222 Rosewood Drive, Danvers, MA 01923; include the code 0021-8669/09 and \$10.00 in correspondence with the CCC.

*Head Transport Aircraft, Institute of Aerodynamics and Flow Technology, Lilienthalplatz 7.

${ }^{\dagger}$ Test Engineer, Ernst-Mach Strasse.

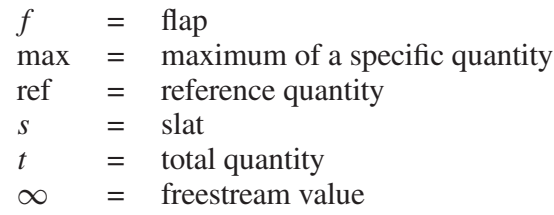

\section{Introduction}

T HE aerodynamic characteristics of commercial aircraft high-lift configurations represent a great challenge with respect to the reliable simulation, either in the wind tunnel or using numerical methods. The reason is basically the variety of different flow phenomena, which are present on such type of configurations, and the geometric complexity of the deployed high-lift devices at the wing leading and trailing edges. Important flow phenomena are pressure- and geometry-induced flow separations, interactions of wall bounded and free shear layers, strong pressure gradients due to a large velocity disparity from low-speed to moderate compressible flows, and strong flow curvature. The main aerodynamic design targets for commercial aircraft high-lift configurations are the maximum attainable lift for the landing configuration and the liftover-drag ratio $L / D$ for the takeoff configuration in the second climb segment $[1,2]$. For the landing configuration with highly deployed slats and flaps, the determination of the maximum attainable lift plays the most important role. The assessment and eventually improvement of the high-lift properties of a configuration requires the identification, localization, and understanding of the effects and features that determine the maximum attainable lift. For high-aspectratio wings and configurations, maximum lift is directly related to the occurrence of flow separation that is strong enough to cover a sufficiently large portion of the wing, overcompensating the lift gain in portions of the wing with attached flow with increasing angle of attack. The mechanisms that cause flow separation and wing stall are quite different. As outlined by Gault in [3] , for a simple single element airfoil, basically four different stall types are observed: thin airfoil stall, leading-edge stall, combined leading- and trailing-edge 
stall, and trailing-edge stall. Having a certain overlap, these stall types occur in the order mentioned before with increasing Reynolds number. The dependency of the aerodynamic properties from the Reynolds number is a typical example of so-called Reynolds number scaling effects, which play an important role when results from subscale wind-tunnel tests have to be extrapolated to flight conditions. In addition, advanced numerical methods for the prediction of complex high-lift flows have to be able to simulate these Reynolds number effects. To ensure this capability of the numerical methods, a thorough validation with suitable test data covering a sufficiently large Reynolds number range is required. Following a comprehensive overview of scale effects in high-lift low-speed flows in [4], basically four sources of direct scale effects are identified:

First, conventional scale effects, which are associated with the reduction of the boundary-layer thickness with increasing Reynolds number, are identified. The reduction of the boundary-layer thickness toward the trailing edge with increasing Reynolds number enables the flow to withstand higher pressure gradients without separating. The effect is favorable and especially relevant for a trailing-edge stall.

Second, bubble-dominated scale effects are associated with the Reynolds number dependent changes in the characteristics of a laminar separation bubble. Especially, the laminar part of a transitional separation bubble is contracting with increasing Reynolds number, and finally the complete bubble vanishes. This favorable scale effect is relevant for a leading-edge type of stall.

Third, slot-flow-dominated scale effects, which apply to multielement airfoils and wings, are identified. The viscous interaction between the wake of an upstream element (e.g., main wing) with the boundary layer of a downstream element (e.g., trailing-edge flap) is affected by Reynolds number. In addition, the size of the geometryinduced separation in the main wing and slat coves is changing with Reynolds number. These scale effects are most important for the setting optimization of the high-lift devices. Depending on the actual situation and loading of the elements, these effects can be favorable or adverse with respect to the high-lift properties.

The fourth source identified is transition-dominated scale effects which act in different ways. For 2-D cases or wings with low sweep, transition moves forward with Reynolds number, leading to a larger extension of the turbulent boundary layer and hence an increased tendency to trailing-edge separation. For swept wings, leading-edge contamination and attachment line transition as well as crossflow instability affect the transition location and the complete flowfield depending on Reynolds number and sweep. Leading-edge contamination and attachment line transition are typical sources for adverse Reynolds number effects at high Reynolds numbers close to flight conditions. Also, relaminarization may occur up to flight conditions usually acting in a favorable manner.

In addition to maximum lift, of course, other high-lift properties are also affected by scaling effects, for example, drag in the linear lift regime is affected by changing the transition location. The preceding listed sources for scale effects apply for simplified configurations, either for airfoils or for unswept or swept high-lift wings with continuous high-lift devices. In these cases, stall is dictated by sectional properties of the wing.

For complete 3-D high-lift transport aircraft configurations with tapered wings, the situation is much more complicated. In principal, the aforementioned aspects also hold for a high-aspect-ratio tapered wing. The wing taper leads to spanwise varying local Reynolds numbers, and, consequently, the scale effects on the maximum attainable lift may change with span. Different scale effects may apply on different spanwise stations of the high-lift wing. Unlike 2-D cases, where the type of stall is reflected in the slope of the lift curve, for 3-D cases, the fact whether the complete wing stalls at a certain angle of attack, or only parts of the wing, while others are still generating lift, also determines the slope of the lift curve around maximum lift. This fact makes it much more difficult to derive a certain type of stall from the lift curve. Moving to the complete aircraft configuration with underwing-mounted engines, there are specifically two critical areas with respect to the determination of maximum lift. The first is the trailing-edge area at the wing root, and the second is the leading-edge area at the nacelle position. Both areas often determine the maximum lift behavior for complete configurations instead of sectionwise lift characteristics. At the wing root, the vortex shed by the slat end together with the large local Reynolds number may provoke trailing-edge separation. The maximum lift behavior can be improved by modifications of the slat end, like slat horns [4]. Concerning engine installation, modern commercial aircraft are equipped with high- to very-high-bypass-ratio engines mounted closely coupled to the wing. The close coupling requires a cutout in the leading-edge high-lift device. The shaping of the cutout edges and the pylon/wing junction is essential to improve the highlift capabilities in this area. In many cases, so-called nacelle strakes are mounted at the forward upper part of the nacelle to improve the local maximum lift behavior. In both areas, at the wing/fuselage junction and at the wing/pylon junction, vortices are generated that interact with the local wing boundary layer by inducing additional velocities. The design philosophy is basically to induce a downwash to suppress separation and to place the upwash at uncritical parts of the flow. Although the vortices themselves may not be strongly dependent on the Reynolds number, the wing boundary layer encounters Reynolds number scaling effects that change its stall behavior. The correct placement of any vortex-inducing device that is supposed to interact with the wing boundary layer therefore relies on the knowledge of the relevant stall characteristics. These devices may not work properly over the whole Reynolds number range if the stall characteristics change significantly. Consequently, the efficiency of such devices is also subject to scaling effects, although they may be regarded as indirect effects. As stated in [4], the scaling effects depend strongly on the specific aircraft, its high-lift system design, and the location and shape of components such as pylon and nacelle. Some examples for scaling effects of existing commercial aircraft are given in $[5,6]$. The extrapolation from subscale Reynolds numbers to flight conditions or the transfer of design solutions from one aircraft to another is usually associated with a high risk. As concluded in [4], a generalization of the Reynolds number scaling effects appears hardly possible, especially for complex 3-D configurations. Currently, the approach to limit the risk of Reynolds number scaling effects in the aircraft design phase before flight testing is twofold: on the one hand, wind-tunnel test facilities are required that are able to simulate the flow around complete high-lift configurations up to flight conditions. Being able to operate under cryogenic conditions, the European Transonic Wind Tunnel (ETW) in Germany is one example of such type of facility. On the other hand, as cryogenic tests are quite expensive, the experimental assessment of the high-lift properties is to be supported by accompanying computational fluid dynamics (CFD) computations using advanced and carefully validated numerical methods.

The European high-lift projects EUROLIFT I and EUROLIFT II have been set up to generate a complete validation database for CFD codes covering the Reynolds number range representative of industrial atmospheric facilities, like the low-speed wind-tunnel (LSWT) of Airbus in Bremen, Germany, up to the high Reynolds numbers representative for flight conditions in the ETW. The EUROLIFT I project has been launched as part of the fifth European framework program in 1999 under the coordination of Airbus-Deutschland. The follow-up project EUROLIFT II, launched in 2004 within the sixth European framework program, is coordinated by DLR. The projects cover experimental as well as extensive numerical activities for the validation and improvement of state-of-the-art CFD codes to predict the flow around commercial aircraft high-lift configurations. An overview of the project structure and some selected results are found in [7]. To be able to separate the different maximum lift determining effects present on typical commercial aircraft configurations and their Reynolds number dependency, the experiments have been carried out starting with a wing/fuselage configuration and a simplified high-lift system, with increasing complexity. The objective of the experimental investigations is not to derive unique scaling rules, but to analyze the impact of different configurative features of a realistic transport aircraft in high-lift configurations, including their scaling effects. A second major objective has been to generate a comprehensive experimental database with well-defined onflow and 
boundary conditions for the validation of numerical methods. The starting point is a simplified wing/fuselage configuration with a continuous full-span slat and flap system without any cutouts; the most complex configuration features a wing/fuselage configuration with a high-bypass-ratio through-flow-nacelle with core-body, realistic cutouts at the pylon/slat junction, as well as a slat horn, and a spanwise gap at the slat/fuselage junction. In contrast to comparative studies as described, for example, in [8], the EUROLIFT experiments are characterized by covering an outstanding Reynolds number range from $R e=1.5 \times 10^{6}$ up to $25 \times 10^{6}$ on a realistic high-lift aircraft configuration with different complexity levels. The present contribution describes results of test campaigns carried out in the ETW in both EUROLIFT projects on four complexity levels of the baseline aircraft configuration. Also being part of EUROLIFT II, selected results of a corresponding campaign in the LSWT of Airbus in Bremen are also included [9]. Special attention is paid to the scaling effects on the different configurations. After a description of the KH3Y model and the ETW as a test facility, the maximum lift properties of the four different configurations will be discussed in detail based on lift curves and drag polars. Finally, Reynolds number scaling effects of all four configurations will be cross plotted, compared, and analyzed by their maximum lift behavior. Because of the amount of available data and sophistication of the problem, the stall behavior of the different configurations and the pressure distributions will be analyzed and discussed in another context. The paper is intended to give a comparative overview about the lift and drag properties obtained in the experiments with the KH3Y configuration in both EUROLIFT projects, with a special focus on the maximum lift values.

\section{KH3Y Configuration}

The baseline model for the present studies is representative of a commercial wide-body twin-jet high-lift configuration. The layout and geometry has been defined by Airbus-Deutschland, denoted as KH3Y. The model is constructed and manufactured by DLR and is denominated as the DLR F11 model. The cruise configuration is equipped with a baseline and a modified leading edge. The baseline wing has a comparatively sharp leading-edge design, resulting in unsatisfying low-speed high-lift characteristics. Therefore, an alternative leading edge with a nose modification has been designed. The modified nose design with a small nose droop improves the maximum lift behavior considerably. With the modified nose design, stall occurs in form of a leading-edge stall for a wide range of Reynolds numbers. The droop nose design also forms the geometrical basis for all high-lift configurations of the KH3Y configuration. The main dimensions of the model are listed in Table 1.

The high-lift system consists of a leading-edge slat and a trailingedge Fowler flap. The slat is subdivided into three parts. The elements are interconnected laterally by latches. The slat is continuously extending up to the wing tip. The local relative slat chord ranges from about $10 \%$ at the inboard pressure section (DV1) to nearly $24 \%$ chord at the most outboard pressure section (DV11). The Fowler flap also consists of three parts. The first one extends up to the wing kink and the second one up to $71 \%$ half-span. The third element extends up to the wing tip. It can be interchanged against a flaperon. For a representative wing section at $68 \%$ half-span, the slat has a local chord length of $17.7 \%$ and the flap of $27.6 \%$, respectively. The highlift system can be mounted in two takeoff settings and one landing setting. For the present studies, only the landing setting is considered, as the major interest lies on the maximum lift performance. The flap

Table 1 Main dimensions of KH3Y model

\begin{tabular}{ll}
\hline \hline Half-span, $s, \mathrm{~m}$ & 1.4 \\
Wing reference area, $A / 2, \mathrm{~m}^{2}$ & 0.41913 \\
Reference chord, $c_{\text {ref }}, \mathrm{m}$ & 0.34709 \\
Aspect ratio, $\Lambda,--$ & 9.353 \\
Taper ratio, $\lambda,-$ & 0.3 \\
Quarter-chord sweep, $\varphi_{25}$, deg & 30 \\
Fuselage length, $l_{\mathrm{Fu}}, \mathrm{m}$ & 3.077 \\
\hline \hline
\end{tabular}

Table 2 Specification of KH3Y model in landing configuration, WP 9

\begin{tabular}{lc}
\hline \hline Slat deflection angle, $\delta_{s}$, deg & 26.5 \\
Slat gap, $g_{s} / c_{\text {ref }},-$ & 0.014 \\
Slat overlap, $o_{s} / c_{\text {ref }},-$ & -0.008 \\
Flap deflection angle, $\delta_{f}$, deg & 32.0 \\
Flap gap, $g_{f} / c_{\text {ref }},-$ & 0.010 \\
Flap overlap, $o_{f} / c_{\text {ref }},-$ & 0.006 \\
\hline \hline
\end{tabular}

can be mounted in several fixed window positions. The reference setting for the landing configuration is denoted as WP 9 (geometrical window point for flap rigging). The device rigging specifications in terms of deflection, gap, and overlap for WP 9 are listed in Table 2 .

For all experiments of the EUROLIFT projects, the model is tested as a half-model to make use of the larger scale compared to fullmodel tests. The model is mounted on a peniche. The KH3Y model consists of a metal main wing structure with detachable leading and trailing edges to allow mounting various high-lift devices. The fuselage shells are manufactured out of carbon fiber. The fuselage as well as the peniche incorporates labyrinth seals adjacent to each other. The peniche is equipped with brush strips adjacent to the test section wall. The effective height of the peniche and the seals in the wind tunnel amounts to $0.101 \mathrm{~m}$. The segments of the high-lift devices have been manufactured to fit gapless in the spanwise direction for the takeoff setting 2. Consequently, the pressure sections of slat and flap are also in line with the fixed wing pressure sections for this setting. To seal the high-lift devices in the landing setting, aluminum alloy tape has been used. At the kink joint, a carbon fiber piece is used to close the flap joint gap. A roughness band with a width of $5 \mathrm{~mm}$ is attached to the fuselage $30 \mathrm{~mm}$ downstream of the fuselage nose. The transition strip is made of carborundum K80. All other components are tested without any transition fixing.

In EUROLIFT I, the model has been used in a wing/fuselage configuration equipped with full-span devices and alternatively a part-span flap with retracted flaperon. For the present comparisons, only the full-span flap configuration is considered. The slat is attached to the main wing using seven slat tracks. The flaps are mounted with five flap tracks and a fixing of the inner flap edge at the fuselage. The flap tracks are covered by flap track fairings. The highlift devices directly intersect with the fuselage for the baseline configuration. The high-lift wing is equipped with 487 pressure taps in 10 pressure sections (DV), as illustrated in Fig. 1. Pressure section 3 is not available for the high-lift model. For an optical monitoring of the flap gap, an onboard miniature camera is mounted thermally insulated in the rear fuselage, observing the area between flap track fairing (FTF) 5 and 7. This baseline configuration is denoted as stage 0 .

For the EUROLIFT II project, the wind-tunnel model is modified toward a more realistic high-lift configuration. Therefore, a slat cutout is introduced at the fuselage and a nacelle is added. At the inner slat end, an onglet serves as a fairing between wing leading edge and fuselage. The inner slat side edge is equipped with a slat horn. For the wing/fuselage/nacelle configuration, the slat has a cutout at the pylon position. For the intersection of the upper pylon and the fixed wing leading edge, another fairing, a so-called bêretbasque is designed to better seal the spanwise gaps between the slat and the pylon. To provoke distinct engine integration effects, this model part has not been used throughout the studies described here. The through-flow nacelle is mounted at $34 \%$ half-span. It is representative of a modern very-high-bypass-ratio engine with a bypass ratio of about 10 with external mixing. The nacelle diameter is $0.155 \mathrm{~m}$, and the overall length amounts to $0.33 \mathrm{~m}$. It is closely coupled to the wing. The through-flow nacelle has an internal corebody nacelle and an internal pylon. It is equipped with a pressure plotting instrumentation at two longitudinal sections of the outer nacelle at radial positions of $30 \mathrm{deg}$ (outboard) and $330 \mathrm{deg}$ (inboard) using 30 pressure taps. The inlet lip design is adjusted to high-lift conditions. A nacelle strake is mounted inboard on the nacelle. For the present investigations, an installation at an azimuth angle of 


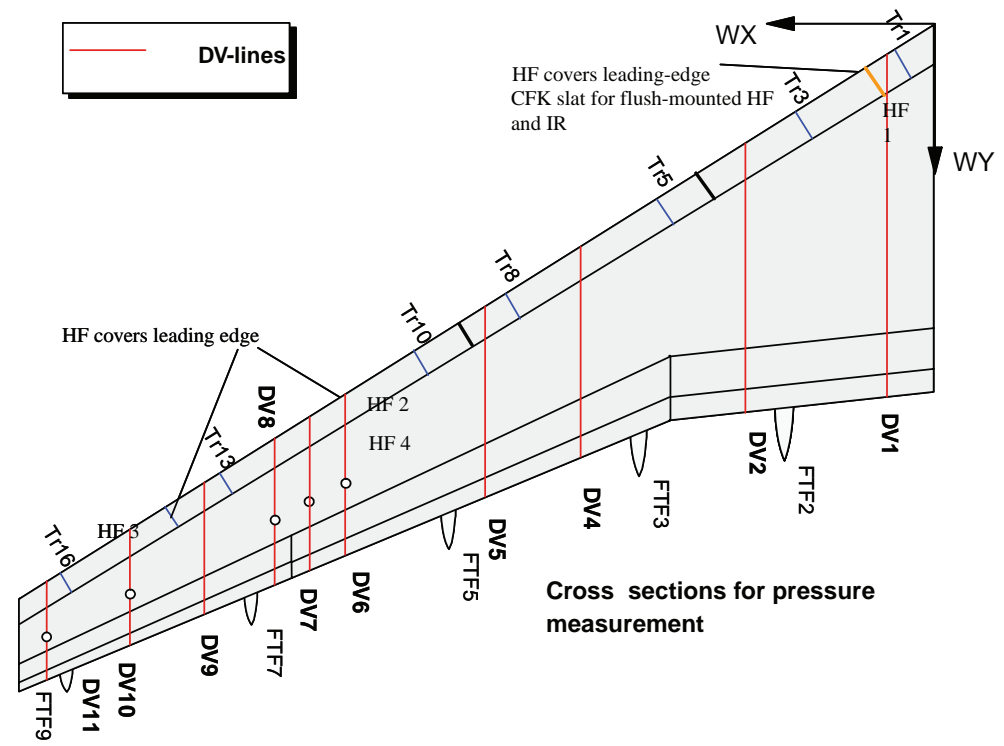

Fig. 1 KH3Y high-lift configuration stage 0 with model instrumentation.

$38 \mathrm{deg}$ is selected. The strake position has been optimized during the low Reynolds number tests in the LSTW of Airbus-Deutschland in Bremen. The strake is made of a $0.5-\mathrm{mm}$ brass sheet. Figure 2 shows the complete EUROLIFT II half-model configuration mounted on the peniche at the top wall of the ETW.

The analysis of the scaling effects will focus on four different levels of complexity, denoted as stage 0 to stage 3 . Stage 0 is the baseline simplified configuration with full-span slat and flap. For stage 1 , a realistic slat end with onglet and slat horn at the fuselage is introduced. For stage 2, the pylon/nacelle components are added. Stage 3 is characterized by the addition of the inboard nacelle strake. The different complexity levels are depicted in Fig. $\underline{3}$.

\section{Wind-Tunnel Campaigns and Test Setup}

The European Transonic Wind-Tunnel facility in Cologne, Germany is a high Reynolds number transonic wind tunnel using nitrogen as the test gas. High Reynolds numbers are achieved under the combined effects of low temperatures and moderately high pressures. The ETW has a closed aerodynamic circuit with a Mach number range from $M=0.15$ to 1.3 . The test section is $2.00-\mathrm{m}$ high, $2.40-\mathrm{m}$ wide, and $8.73-\mathrm{m}$ long. The test section is equipped with removable inserts in the bottom and side walls. These inserts can be selected to yield slotted or solid walls depending on the application. For half-model testing, the top wall is always closed by design and it is from this wall that half-models are supported. The slots in the

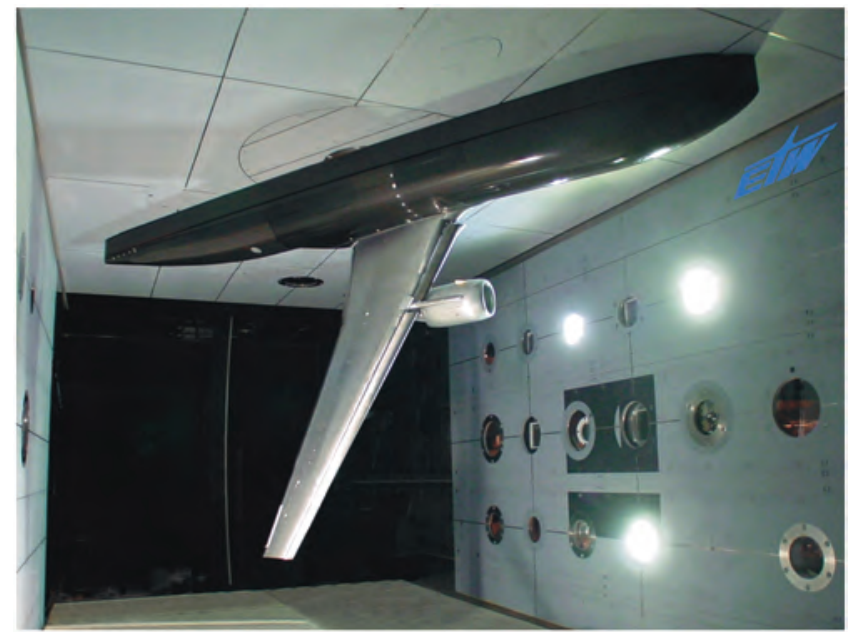

Fig. 2 KH3Y stage 3 high-lift configuration model in ETW. bottom wall are normally closed for half-model testing. The slots in each of the side walls can be opened to reduce blockage, but, to generate well-defined tunnel conditions for validation and scheduled in-tunnel CFD computations, all test section walls remained closed in the EUROLIFT studies. The bottom wall is slightly divergent to compensate boundary-layer displacement effects.

Concerning the measured data, the focus is on the wing and nacelle pressure measurements and on total force determination with the ETW half-model balance. This balance is placed in a thermal enclosure. It is essentially a five-component measuring device (excluding side force, which is relatively insensitive). Each balance beam is instrumented with two sets of strain gauges measuring each load component. A comprehensive thermal control system ensures that the balance is decoupled from the ETW's variable temperature operating environment.

In addition to pressure and force measurements, minitufts are applied to the wing upper surface in the area of the engine mounting to provide additional flow visualization of the wing stalling process.

One of the objectives of the test in the ETW has been to demonstrate the capability of measuring the deformations of high-lift devices with an enhanced photogrammetric system in cryogenic conditions. Especially for the higher total pressure conditions up to 4.5 bars, wing deformation plays a nonnegligible role. The determination of the wing and the high-lift system deformation is considered essential. For this purpose, an existing stereo pattern tacking (SPT) system has been enhanced. In addition to the two SPT cameras installed in the tunnel centerline for the deformation detection of the complete wing, two cameras were installed behind the windows of the bottom line to monitor a certain region of the flap. This second set of cameras belongs to the enhanced stereo pattern tracking (ESPT) system (see Fig. 4).

The SPT technique relies on dots applied on the wing surface. Two cameras monitor the position of each of these dots at discrete model attitudes and under various testing conditions. The volume, in which the wing deforms have to be previously calibrated with a special frame, is fitted with 30 bulbs. The coordinates of these bulbs are known accurately and are correlated to the positions of the bulbs on the images taken by the two cameras. After an optical definition of the dots within the system, the SPT system tracks the position of the dots and converts the recorded information in wing twist and bending. Most of the fixed wing and a portion of the flap between flap track fairings FTF5 and FTF7 have been equipped with SPT/ESPT dots. The SPT/ESPT measurements revealed the twist and bending for the fixed wing and the flap.

The test data under consideration have been collected during three test campaigns in the ETW throughout the runtime of both EUROLIFT projects. The first ETW test campaign took place in the 

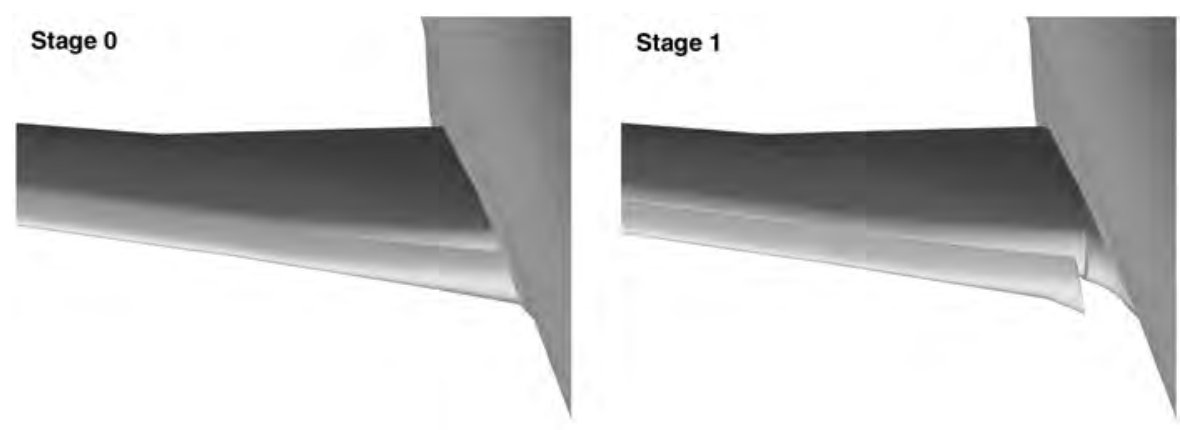

a)
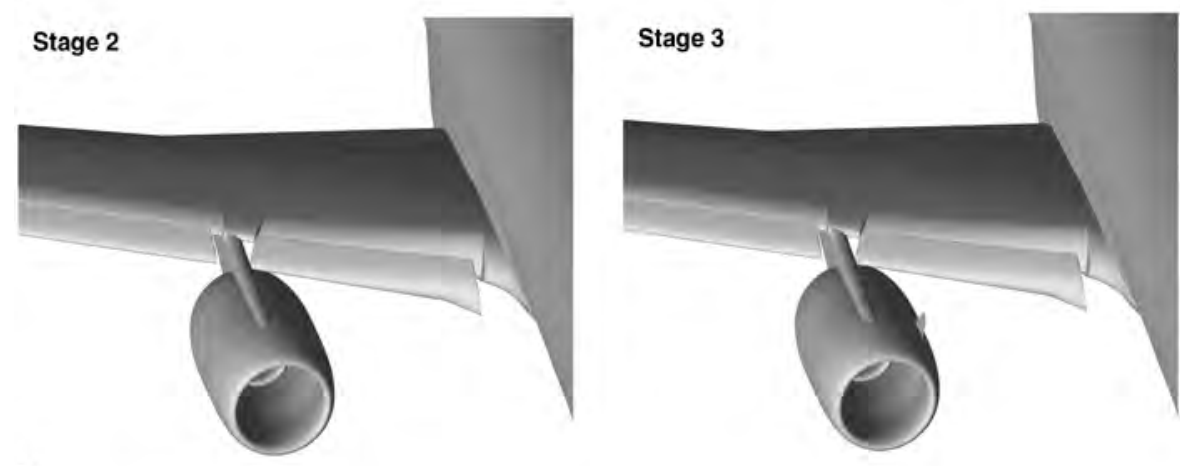

b)

Fig. 3 Complexity levels of KH3Y high-lift configuration a) without nacelle and b) with nacelle.

summer of 2002 in the framework of EUROLIFT I. In this campaign, the data for configuration stage 0 have been taken within a Reynolds number range from $R e=1.45 \times 10^{6}$ up to $15 \times 10^{6}$. The second campaign in the spring of 2005 was part of EUROLIFT II. In this campaign, data for configuration stages 1,2 , and 3 have been recorded within a Reynolds number range from $R e=6.4 \times 10^{6}$ up to $25 \times 10^{6}$. The last ETW test campaign took place in the spring of 2006. The main objective of this campaign has been the demonstration of performance benefits due to numerical flap setting and shape optimization. Selected repeat measurements on configuration stage 2 have also been carried out in the Reynolds number range from $R e=5 \times 10^{6}$ up to $20 \times 10^{6}$. These ETW tests are accompanied by tests in the low-speed tunnel of Airbus-Deutschland in Bremen in early 2005 for $R e=1.4 \times 10^{6}$. The main focus of this atmospheric test has been to gather detailed flowfield information on the vortex dominated interaction of the high-lift wing with engine, pylon, and strake using surface and field measuring techniques such as oil flow, hot films, and three-component particle image velocimetry. A description of the results of the LSWT test is given in [9].

\section{Experimental Results}

The results analyzed in the following chapters have been gathered in the ETW for an onflow Mach number of $M_{\infty}=0.2$ with the highlift devices in landing setting WP 9. The discussion of the high-lift behavior of the different configurations will be done by a sequential quantitative analysis of the lift curves and drag polars of the single configuration stages for different Reynolds numbers. All lift and drag plots use the same origin, so that the graphs can be directly compared. Next, the quality of the data will be assessed by highlighting exemplary the short-term repeatability (STR) based on data of the stage 2 configuration for a medium Reynolds number and different windtunnel runs. The effect and possible impact of different dynamic pressures and total temperatures will be discussed by comparing two

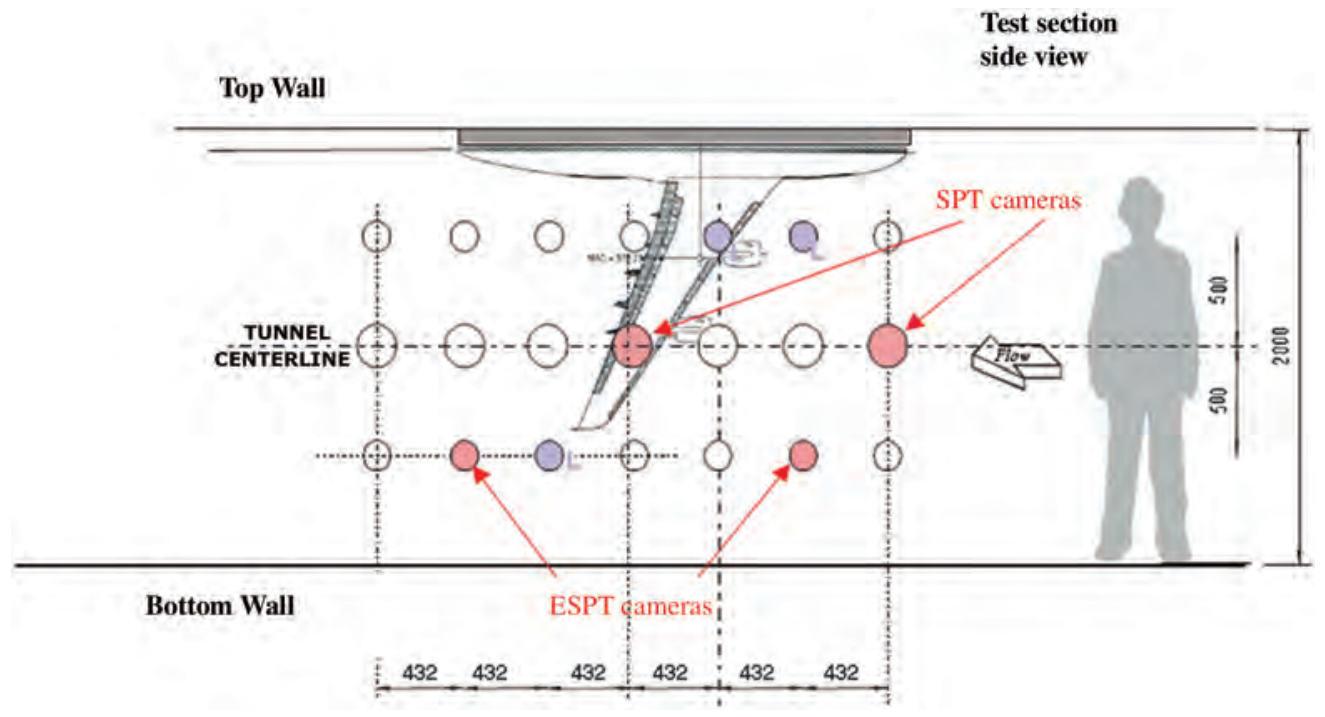

Fig. 4 Setup for SPT/ESPT measurements in ETW. 
different parameter combinations for the same Reynolds number. After this, the wing deformation will be analyzed in terms of wing twist and bending, measured with stereo pattern tracking techniques. Finally, an overview of the achieved maximum lift values for all configurations and Reynolds numbers will be presented.

\section{A. Configuration KH3Y Complexity Level Stage 0}

The stage 0 configuration tested in the framework of EUROLIFT I represents the most simplified configuration of the KH3Y model. It consists of a continuous full-span slat and flap. Both intersect with the fuselage without any spanwise gap (see Fig. 3a). To achieve a Reynolds number variation from $R e=1.45 \times 10^{6}$ up to $15 \times 10^{6}$, the dynamic pressure is varied from $q=2.4$ up to $6.9 \mathrm{kPa}$. The total temperature varies consistently from $T_{t}=300 \mathrm{~K}$ down to $115 \mathrm{~K}$. The lowest Reynolds number has been selected to have a direct link to the low Reynolds number wind-tunnel tests in the LSWT. For this purpose, a Mach number variation has also been carried out, testing for a Mach number of $M=0.176$ as well as for $M=0.2$. As shown in [10], the comparisons revealed that the difference in maximum lift due to the different Mach numbers results in an at most 2 lcts (lift count $=0.01$ ) lower maximum lift for the higher Mach number. As shown in Fig. 5, the slope of the lift curve is comparatively smooth for configuration stage 0 . This behavior does not change with Reynolds number, indicating that the stall type is not affected by the Reynolds

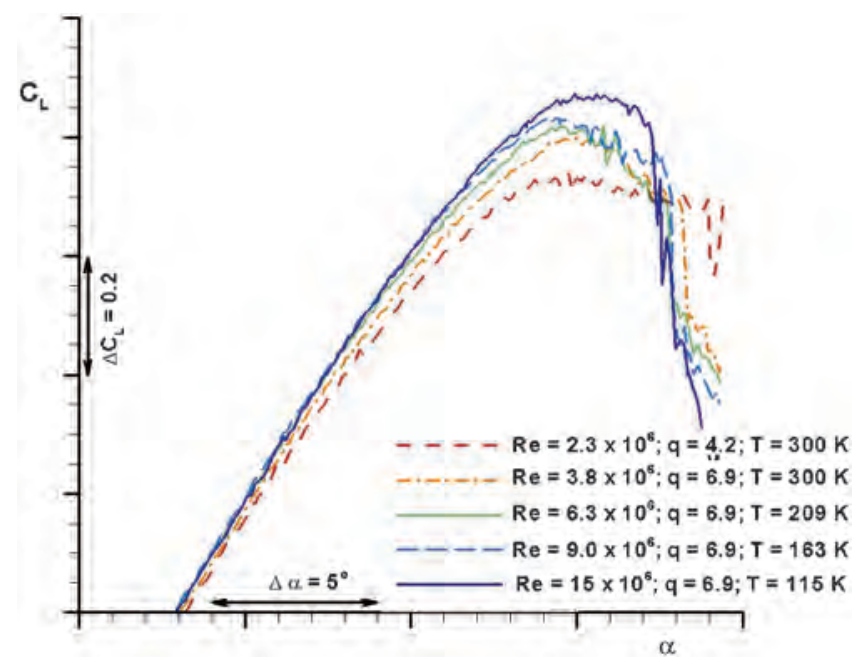

Fig. 5 Lift curve for different Reynolds numbers for KH3Y complexity stage 0. number. The wiggles found in the lift curves are due to continuous pitch data acquisition.

Following an analysis in [10], stall is determined in the chordwise direction by a trailing-edge separation on the main wing and the flap, consistent with the smooth lift curve around maximum lift. This holds for all considered Reynolds numbers. In the spanwise direction, stall begins for the low Reynolds numbers over the inner part of the wing (DV1 and DV2) and the spreads outboard, whereas, for intermediate and higher Reynolds numbers, stall starts outboard and then spreads to the inboard portion of the wing. For stage 0 , a difference in lift coefficients of about 3 lcts is already present in the linear range of the lift curve. Maximum lift increases monotonously with Reynolds number. The Reynolds number effect causes a difference in maximum lift of about 14 lcts. The angle of attack $\alpha\left(C_{L, \max }\right)$, at which maximum lift is reached, decreases slightly except for the highest Reynolds number. The difference in $\alpha\left(C_{L, \max }\right)$ is about $1 \mathrm{deg}$.

The total drag, depicted in Fig. 6, is consistently higher for lower Reynolds numbers $R e=2.3 \times 10^{6}$ and $3.8 \times 10^{6}$ than that for the high Reynolds numbers. Obviously, this effect is driven by the decreased pressure drag due to the smaller boundary-layer displacement and not by laminar portions of the flow at the leading edges. In the linear lift range, the difference in total drag amounts up to $23 \mathrm{dcts}$ (drag count $=0.0001$ ); for minimum drag, the difference is about 53 dcts. As the enlarged extract shows, the minimum total drag is found for $R e=9 \times 10^{6}$ instead of for the highest Reynolds number. As these results are obtained for considerable negative angles of attack, this tendency may not be overstressed.

\section{B. Configuration KH3Y Complexity Level Stage 1}

Basically, the difference between configuration stage 0 and 1 is the spanwise cutout of the slat at the fuselage. During the EUROLIFT II project, a modified inboard slat with a slat horn is manufactured as well as an onglet, which is attached to the fuselage as shown in Fig. 3a. Especially, the slat horn is introduced to minimize the adverse gap effects (see [4]). The Reynolds number has been varied from $R e=6.5 \times 10^{6}$ up to $25.5 \times 10^{6}$, the dynamic pressure varies from $q=4.2 \mathrm{kPa}$ up to $12.6 \mathrm{kPa}$, being significantly higher than for the stage 0 configuration. The total temperature is $T_{t}=138 \mathrm{~K}$ for the lowest Reynolds number and $T_{t}=115 \mathrm{~K}$ for all others. To withstand the higher dynamic pressures, new reinforced slat tracks have been manufactured and used. When comparing the slope of the lift curve around maximum lift in Fig. 7 to that of configuration stage 0 , it has to be taken into account that the forces for stage 1 have been taken in pitch-pause mode with $\Delta \alpha \sim 1 \mathrm{deg}$, whereas the stage 0 data have been recorded in continuous mode. The stall is driven by trailing-

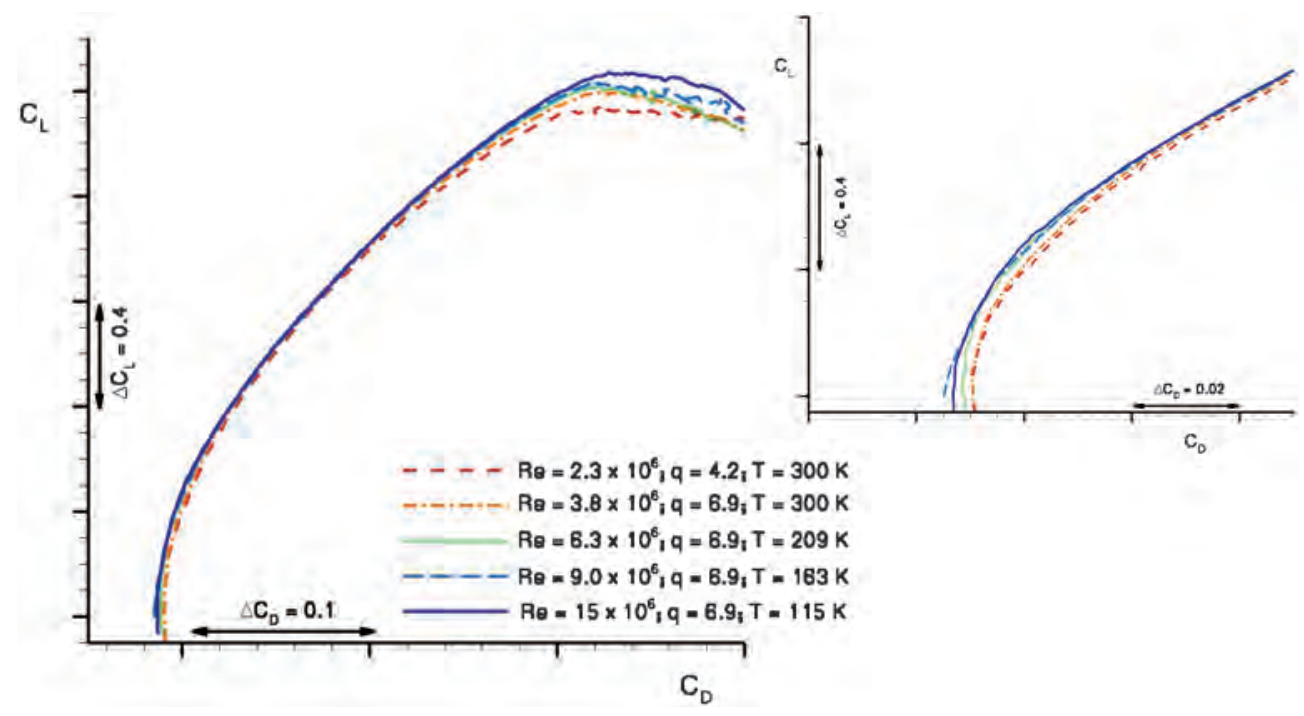

Fig. 6 Drag polars for different Reynolds numbers for KH3Y complexity stage 0. 


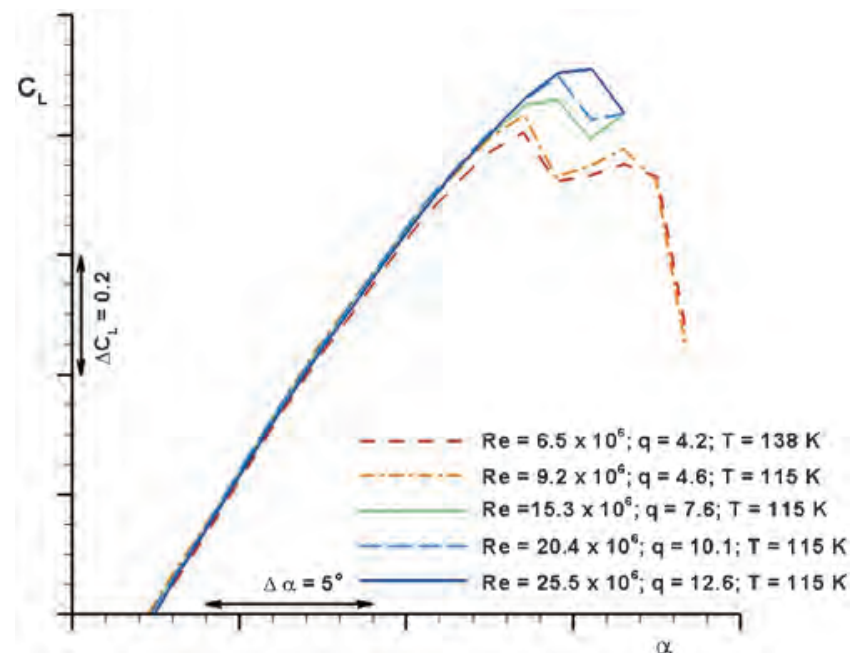

Fig. 7 Lift curves for different Reynolds numbers for KH3Y complexity stage 1 .

edge separation on the fixed wing and flap in the outboard wing area. In the linear lift range, the Reynolds number influence leads to a lift difference of 1.5 lcts, half the value of that for stage 0 . Maximum lift is again increasing monotonously with Reynolds number. Also, the difference in maximum lift of about 10 lcts is less pronounced than for stage 0 . It has to be taken into account that the considered Reynolds number range and its limits between the stage 0 and stage 1 data is different. If the Reynolds number range from $R e=6 \times 10^{6}$ up to $15 \times 10^{6}$ is considered, which is measured for both configurations, the difference between stage 0 and stage 1 in $\Delta C_{L, \max }$ is about 1 lct. The angle of attack $\alpha\left(C_{L, \max }\right)$, at which maximum lift is reached, is constantly increasing up to the highest Reynolds number with a maximum difference in $\alpha\left(C_{L, \max }\right)$ of about $2 \mathrm{deg}$.

The total drag behavior, shown in Fig. $\underline{8}$, is similar to that of stage 0 . In the linear lift range, the difference in total drag amounts up to 45 dcts; for minimum drag, the difference is about 50 dcts. The drag differences due to Reynolds number effects in the linear range and for minimum drag are less pronounced than for stage 0 .

\section{Configuration KH3Y Complexity Level Stage 2}

Configuration stage 2 is equipped with nacelle and pylon, necessitating a spanwise cutout of the slat at the engine position due to the close coupling of the components. The Reynolds number and dynamic pressure range, as well as the total temperatures, are in principal the same as for configuration stage 1. Figure 9 shows the corresponding lift curves. Comparing the lift values with that of stage 1 underlines that the nacelle installation and the slat cutout cause significant losses in maximum lift. First evaluations of the minituft videos reveal that, in contrast to stage 0 and stage 1 , stall for configuration stage 2 begins at the fixed wing trailing edge in the area behind and slightly inboard of the spanwise nacelle position. This is in agreement with observations reported in [4] and may be considered as a typical engine installation effect for a high-lift configuration. The order of maximum lift with Reynolds number differs from the previous cases. For configuration stage 2, the highest maximum lift occurs for the lowest evaluated Reynolds number of $R e=6.5 \times 10^{6}$, clearly indicating an adverse scaling effect for higher Reynolds numbers. Compared to the lowest maximum lift value, the difference in maximum lift amounts to about 6 lcts. The difference in $\alpha\left(C_{L, \max }\right)$ between $R e=6.5 \times 10^{6}$ and $R e=25.5 \times$ $10^{6}$ amounts to about $1.5 \mathrm{deg}$. Following the minituft evaluation, the principal stall mechanism for the highest and lowest Reynolds number is identical. For the other Reynolds numbers, considerably smaller differences in maximum lift and $\alpha\left(C_{L, \max }\right)$ are observed. In the linear range, lift differs by about $3.5 \mathrm{lcts}$ for all analyzed Reynolds numbers. Except for the highest Reynolds number of $R e=25.5 \times$ $10^{6}$, the sequence of lift with Reynolds numbers follows the typical order according to first-order scaling effects caused by decreasing displacement thickness in the linear lift range. This is confirmed by the drag polars in Fig. 10, where the lowest Reynolds number causes the highest total drag. Again, the highest Reynolds number does not follow this sequence, featuring a total drag close to the curve for $R e=15.3 \times 10^{6}$. In the linear lift range, the difference in total drag due to Reynolds number effects amounts to $86 \mathrm{dcts}$; for minimum drag, the difference is about 73 dcts. It follows that the difference in total drag with Reynolds number is about twice as high for the configuration with installed nacelle than for the clean high-lift wing regarding the same Reynolds number range. For the highest Reynolds number in the linear lift range, the increase in total drag due to the nacelle installation amounts to about 110 dcts.

The reason for the adverse scaling effects on maximum lift needs further analysis. Depending on the available measured data, it has to be checked whether transitional effects at the wing or nacelle leading edges play a role for the maximum lift behavior and how the flow mechanisms work.

\section{Configuration KH3Y Complexity Stage 3}

For configuration stage 3 , a nacelle strake is added to configuration stage 2 at the upper inboard portion of the nacelle. The strake position

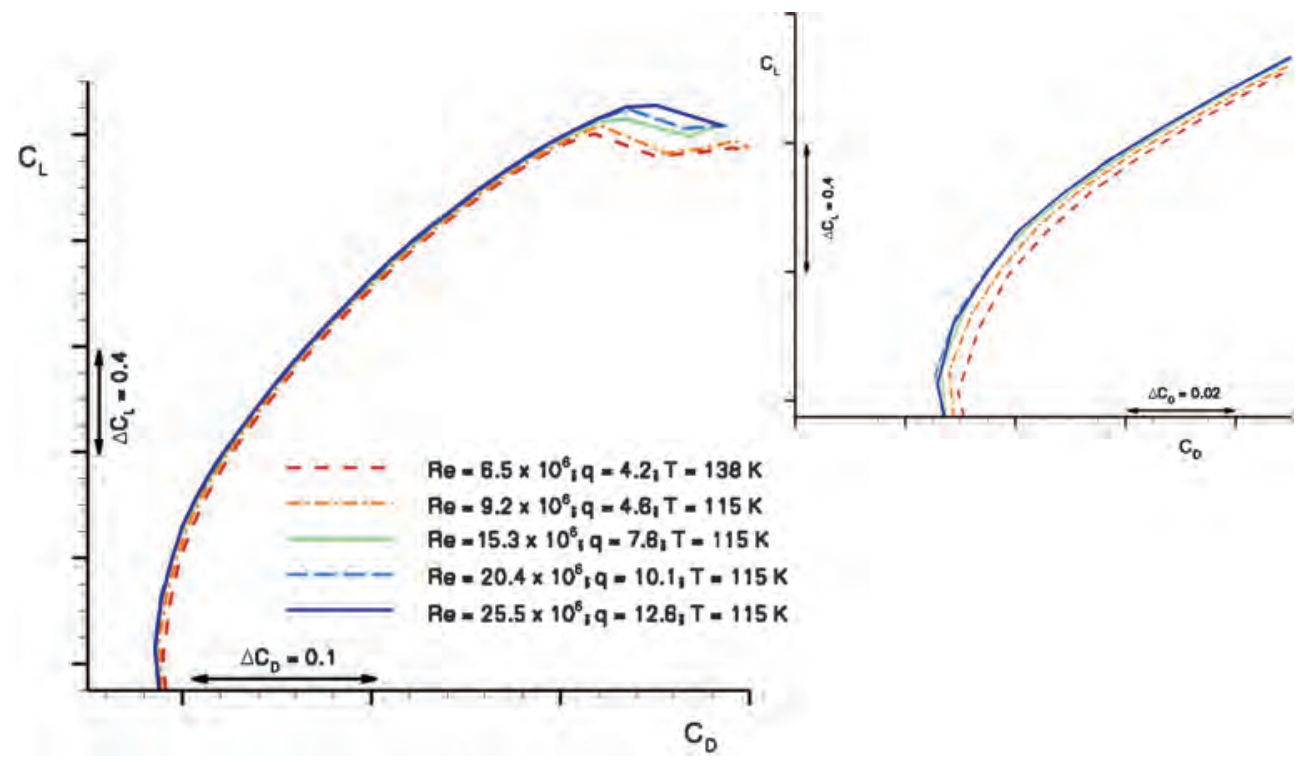

Fig. 8 Drag polars for different Reynolds numbers for KH3Y complexity stage 1. 


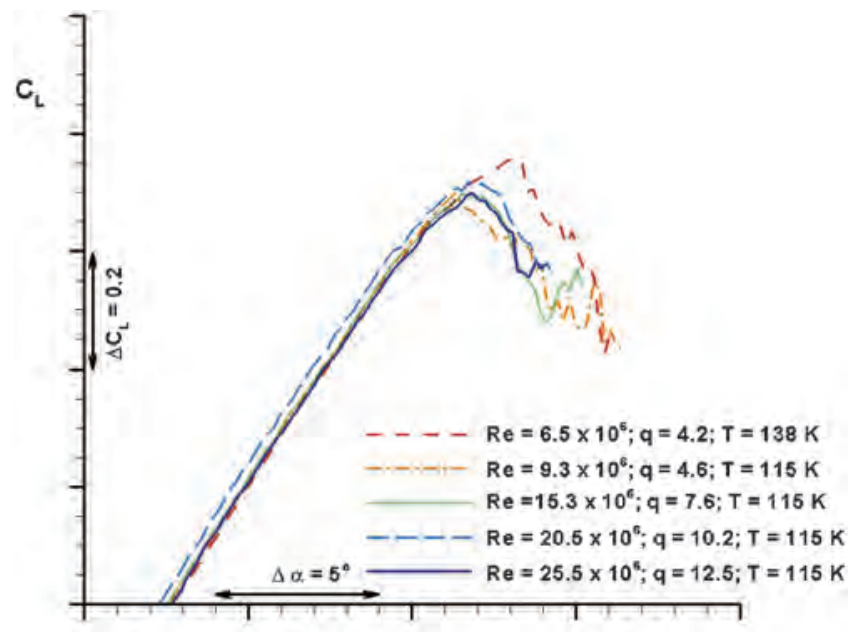

$\alpha$

Fig. 9 Lift curves for different Reynolds number for KH3Y complexity stage 2.

has been optimized in an atmospheric wind-tunnel test campaign within the framework of EUROLIFT II in the Airbus LSWT [9]. The onflow parameters are again in the range of the previous stages 1 and 2. As Fig. 11 documents, the strake has a beneficial influence on the maximum lift values. The slope of the curves is not significantly different from that of stage 2 , but the maximum lift values are clearly higher. The minituft videos reveal that stall is again triggered in the trailing-edge area of the fixed wing at the nacelle position. In contrast to the behavior of configuration stage 2 , separation now starts outboard of the spanwise nacelle position. The differences in maximum lift due to the Reynolds number variation amounts to $\Delta C_{L, \max }$ $\sim 5.5$ lcts. They are comparatively smaller than for stage 2 . The adverse effects are alleviated. Yet, the highest maximum lift is not obtained for the highest Reynolds number, but for $R e=15.2 \times 10^{6}$. The difference in $\alpha\left(C_{L, \max }\right)$ amounts to less than $1 \mathrm{deg}$. Lift differs by about 5.5 lcts in the linear range. In contrast to the results for configuration stage 2 , the sequence of the lift curves at maximum lift is now basically maintained in the linear lift range. The lift curve for $R e=15.2 \times 10^{6}$ appears to have a smaller $\alpha_{0}$ by about $0.5 \mathrm{deg}$ resulting in higher lift values for constant $\alpha$.

The drag polars in Fig. 12 reveal a somewhat unusual behavior. In the linear lift range, the polars for $R e=15.2 \times 10^{6}$ and $R e=$ $25.3 \times 10^{6}$ nearly lie on top of each other, whereas the other Reynolds numbers have higher total drag values. The maximum difference in total drag due to Reynolds number effects amounts to

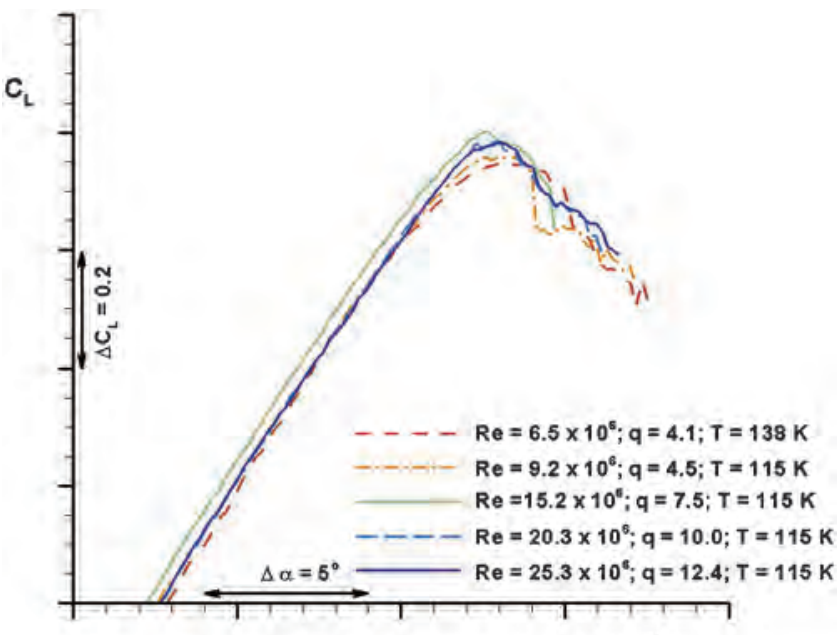

$\alpha$

Fig. 11 Lift curves for different Reynolds number for KH3Y complexity stage 3 .

75 dcts. For minimum drag, the total drag decreases consistently with increasing Reynolds number with a difference of about 59 dcts between the polars.

\section{E. Repeatability for Configuration KH3Y Complexity Level Stage 2}

For configuration stage 2, repeatability is evaluated for a Reynolds number of $R e=6.5 \times 10^{6}$ in cryogenic conditions for the same total temperatures and dynamic pressures. Results are presented in Figs. 13 and 14. Short-term repeatability within the same test campaign, indicated as the difference between the solid reference curves and the long-dashed curves, reveals a good reproduction capability. As a reference, the data of the repeat runs are first plotted within the same range of the axis as the previous lift curves and drag polars (see Figs. 13a and 14a).

In addition, the lift values are subtracted for constant angle of attack and plotted in Fig. 13b. The difference in lift is less than 1 lct up to maximum lift. Beyond maximum lift, the flow becomes increasingly unsteady, causing stronger oscillations in the lift deviation between the two measurements above and below the $x$ axis up to about 6 lcts.

The comparison of the drag polars is plotted in Fig. 14a. The difference in drag at constant lift is evaluated in Fig. 14b. In the linear lift range below maximum, a difference in drag between 10 and 15 dcts is observed. This difference is increasing by about 5 dcts when maximum lift is approached.

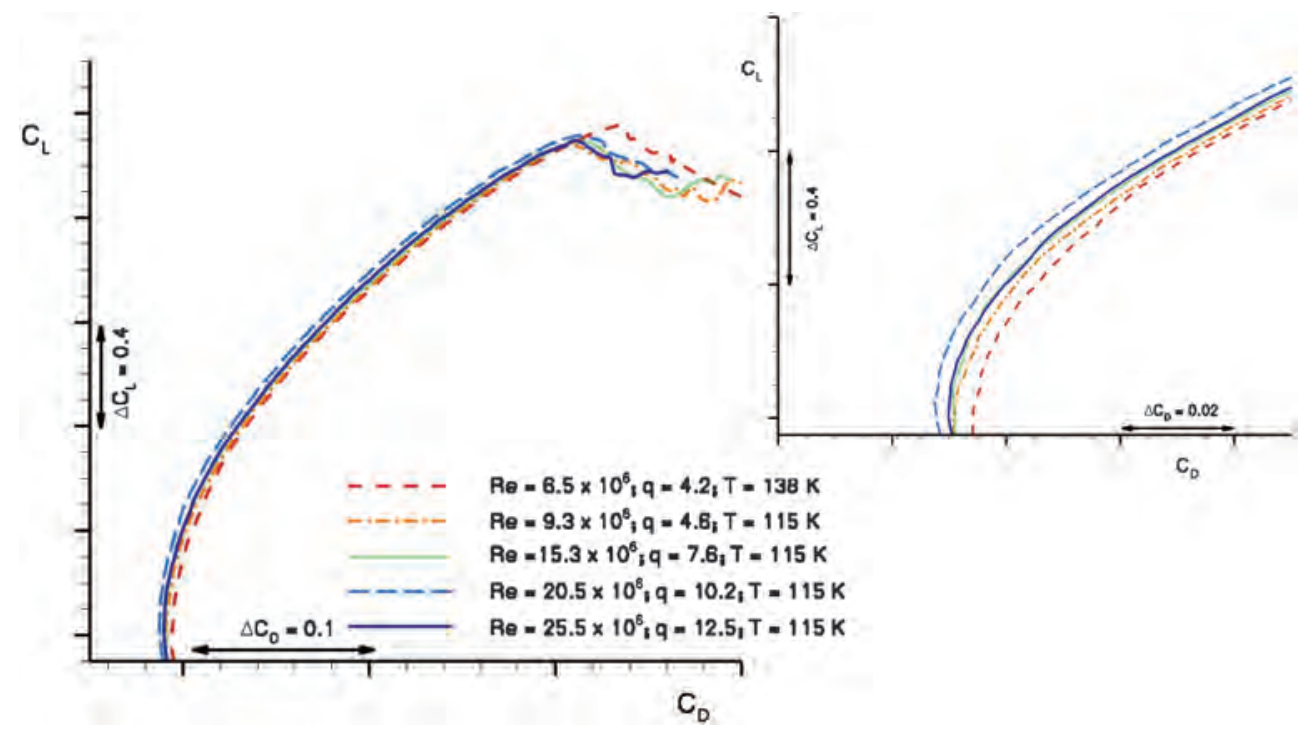

Fig. 10 Drag polars for different Reynolds number for KH3Y complexity stage 2. 


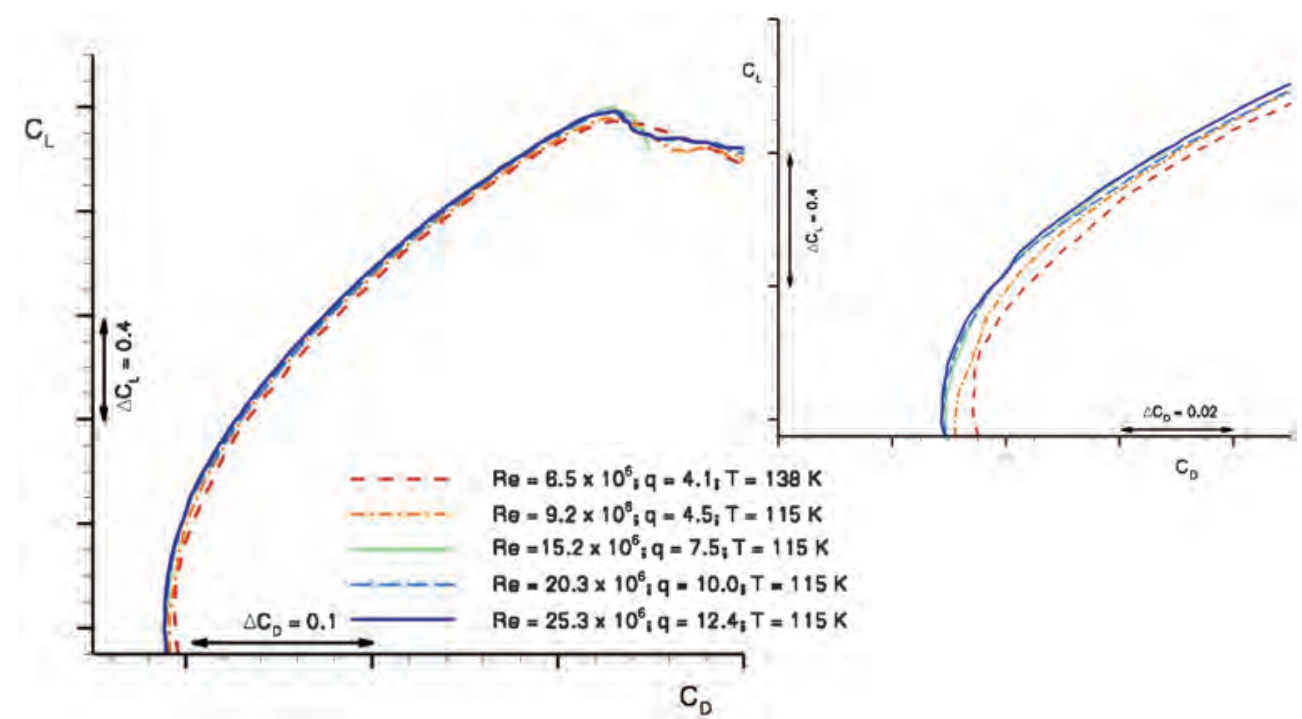

Fig. 12 Drag polars for different Reynolds number for KH3Y complexity stage 3.

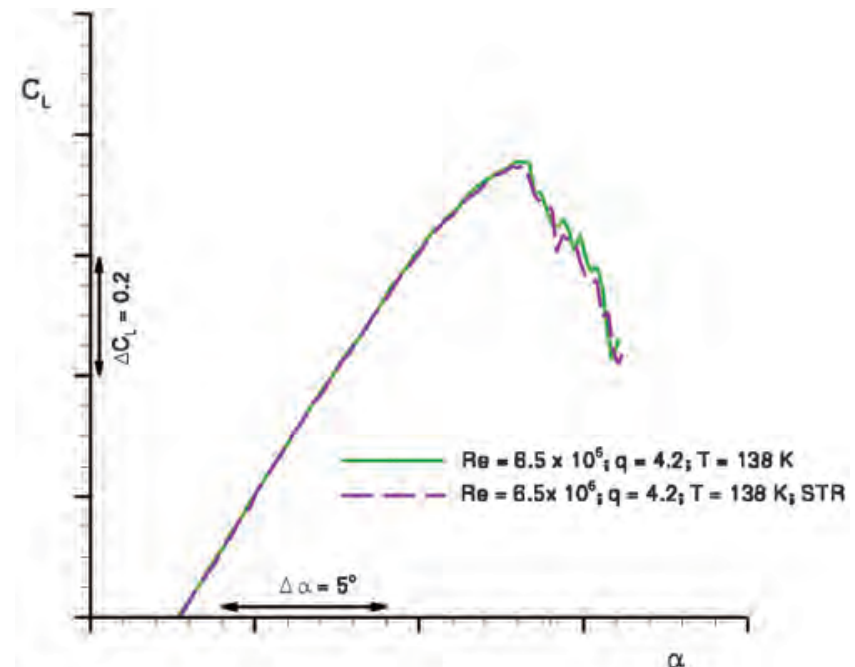

a)

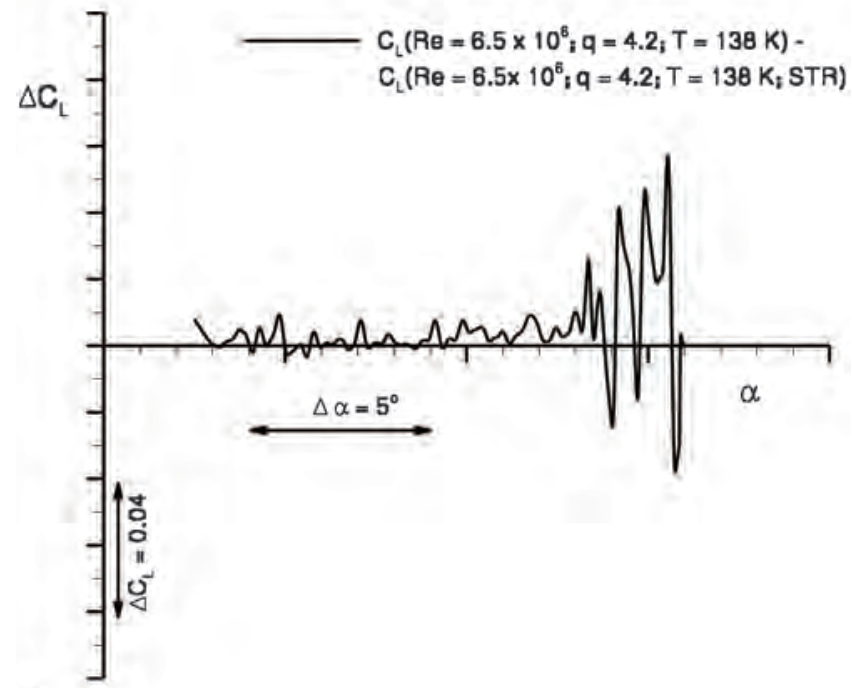

b)

Fig. 13 STR for KH3Y complexity stage 2: a) lift curves for STR, b) lift difference.

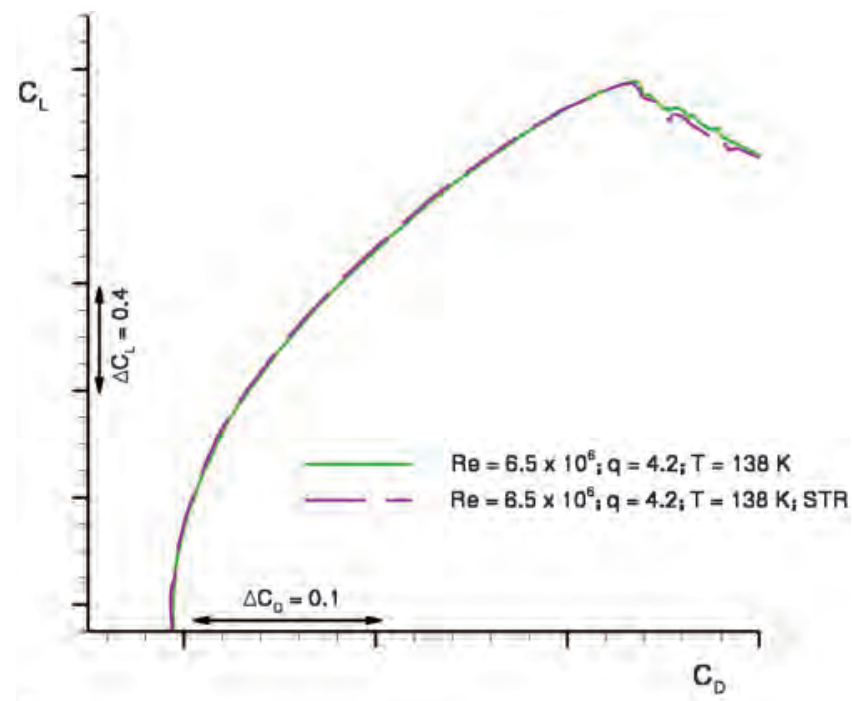

a)

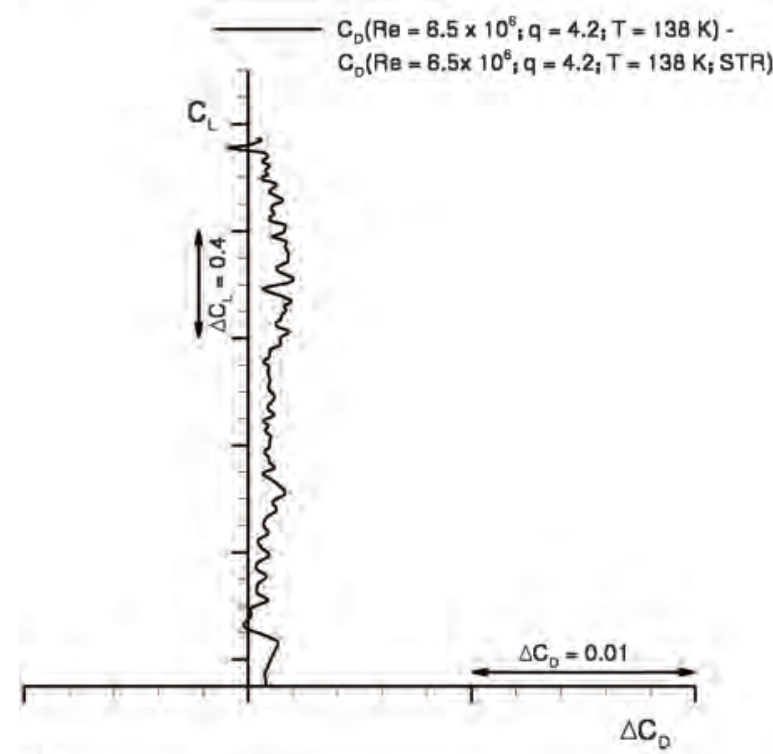

b)

Fig. 14 STR repeatability for KH3Y complexity stage 2: a) drag polars, b) drag difference. 


\section{F. Influence of Total Pressure on Configuration KH3Y Complexity} Level Stage 2

To increase the Reynolds numbers up to flight conditions, ETW makes use of cryogenic testing at very low temperatures as well as increasing dynamic pressure. The latter means directly affects the deformation of the wind-tunnel model and leads to changes in the aerodynamics. In addition to the effects of twist and wing bending on a clean wing, the rigging of the high-lift devices is also affected for high-lift configurations. The resulting changes in gaps and overlaps potentially influence the high-lift aerodynamics significantly. A socalled true Reynolds number variation therefore requires varying the total temperature for constant values of dynamic and total pressure to prevent an unintentional influence of the deformation on the aerodynamics of the high-lift wing. Because of efficiency reasons, a combination of simultaneous changes in temperature and pressure is often chosen, as in the present study. In this case, it is especially important to assess the influence of the dynamic pressure on the resulting aerodynamics. For configuration stage 2, the effect of different dynamic pressures on the lift and drag values is demonstrated for $R e=6.5 \times 10^{6}$. This is the same Reynolds number as for the repeatability, but for different total temperatures.

The lift curves in Fig. 15 exhibit a difference in maximum lift of slightly more than 2 lcts for a dynamic pressure, which is more

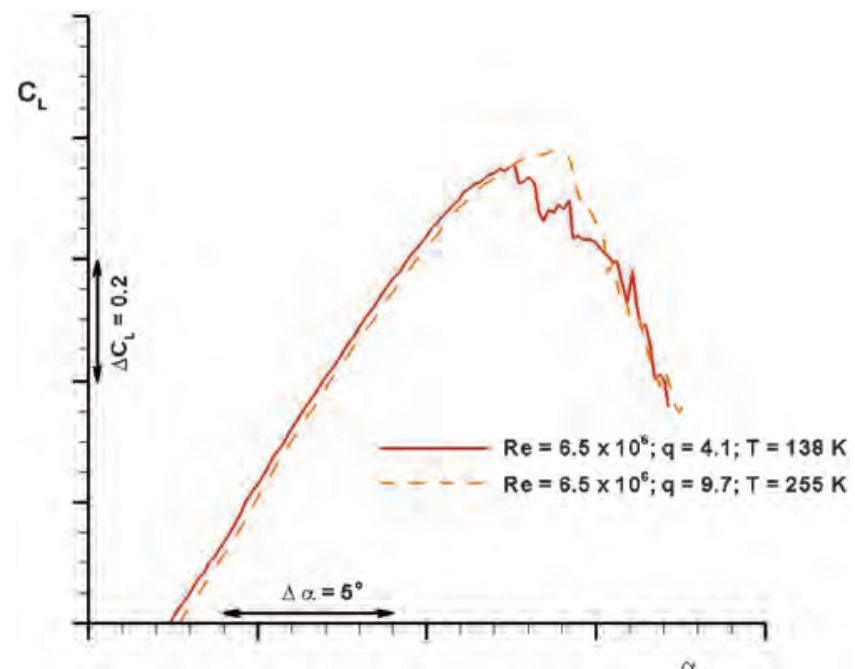

Fig. 15 Lift curves for different total pressure levels for KH3Y complexity stage 2 .

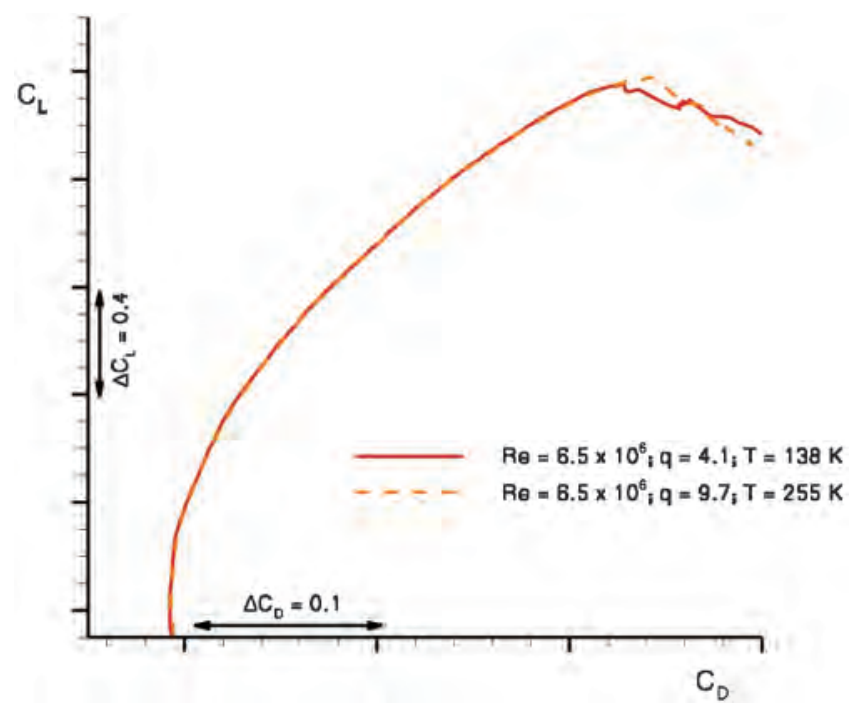

Fig. 16 Drag polars for different total pressure levels for KH3Y complexity stage 2 . than doubled. The difference decreases slightly in the linear lift range. The corresponding angle of attack for maximum lift differs by $\Delta \alpha\left(C_{L, \max }\right) \sim 1.3 \mathrm{deg}$. The higher dynamic pressure results in higher maximum lift values and $\alpha\left(C_{L, \max }\right)$.

The influence on the total drag is depicted in Fig. 16 in the direct crossplotting of the drag polars. The difference in total drag for the same Reynolds number but different dynamic pressures is evaluated in Fig. 17. In the linear lift regime, the difference varies between 0 and nearly $\overline{10}$ dcts; close to maximum lift, the difference increases according to the different maximum lift values to about 20 dets. Overall, the drag for the measurement with higher $q$ and higher temperature is higher than that of the lower $q$ and temperature. Given the drag deviations evaluated for the short-term repeatability, no distinct influence of the different total pressure is found in the drag behavior.

\section{G. Wing and Flap Deformation for Configuration KH3Y Complexity Level Stage 1}

As shown in the previous section, wing deformation can produce a nonnegligible influence on the aerodynamics, especially for maximum lift. For validation purposes of CFD codes, it is essential to measure the deformation of the high-lift wing. In the present context, this has been done using the stereo pattern tracking technique in two different versions. As mentioned in Sec. II, the main wing and parts of the flap are equipped with markers. Model deformation is measured using the SPT technique for the wing and the ESPT technique for the flap. An example of the measured deformation in terms of wing twist for various lift coefficients is presented in Fig. 18 for $\operatorname{Re}=15 \times 10^{6}$.

As expected, wing twist increases nonlinearly with strongest spanwise gradients at about $60 \%$ half-span. The twist is directly linked to the wing loading. From about $95 \%$ half-span up to the wing tip, the wing twist has reached its maximum values. The largest twist angles of the fixed wing are close to $-1 \mathrm{deg}$ for lift coefficients in the range of maximum lift. The twist of the flap reacts differently. For lift coefficients larger than one, the inboard edge of the flap shows higher negative twist than the outboard edge being a result of the flap rigging at the tracks and the spanwise joints between the flap elements.

As sketched in Fig. 19, the situation for the wing bending is, in principal, similar as far as the dependency from the wing loading is concerned. The curves for the bending are quite smooth with a good agreement between the wing measurements using SPT and the flap measurements using ESPT. The maximum bending amounts to $40 \mathrm{~mm}$ for a lift coefficient slightly below maximum lift.

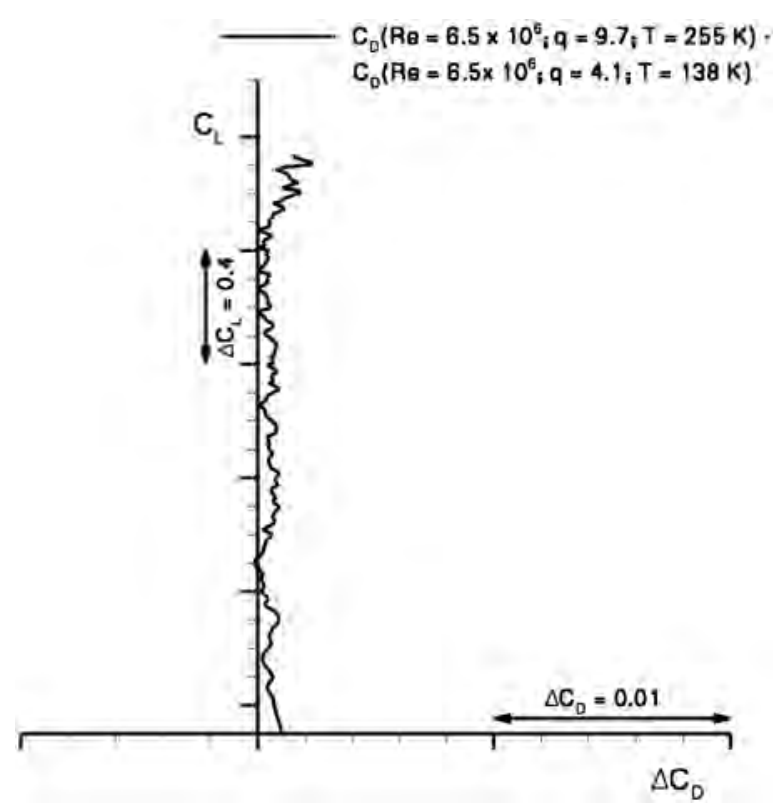

Fig. 17 Drag difference for different total pressure levels for KH3Y complexity stage 2 . 


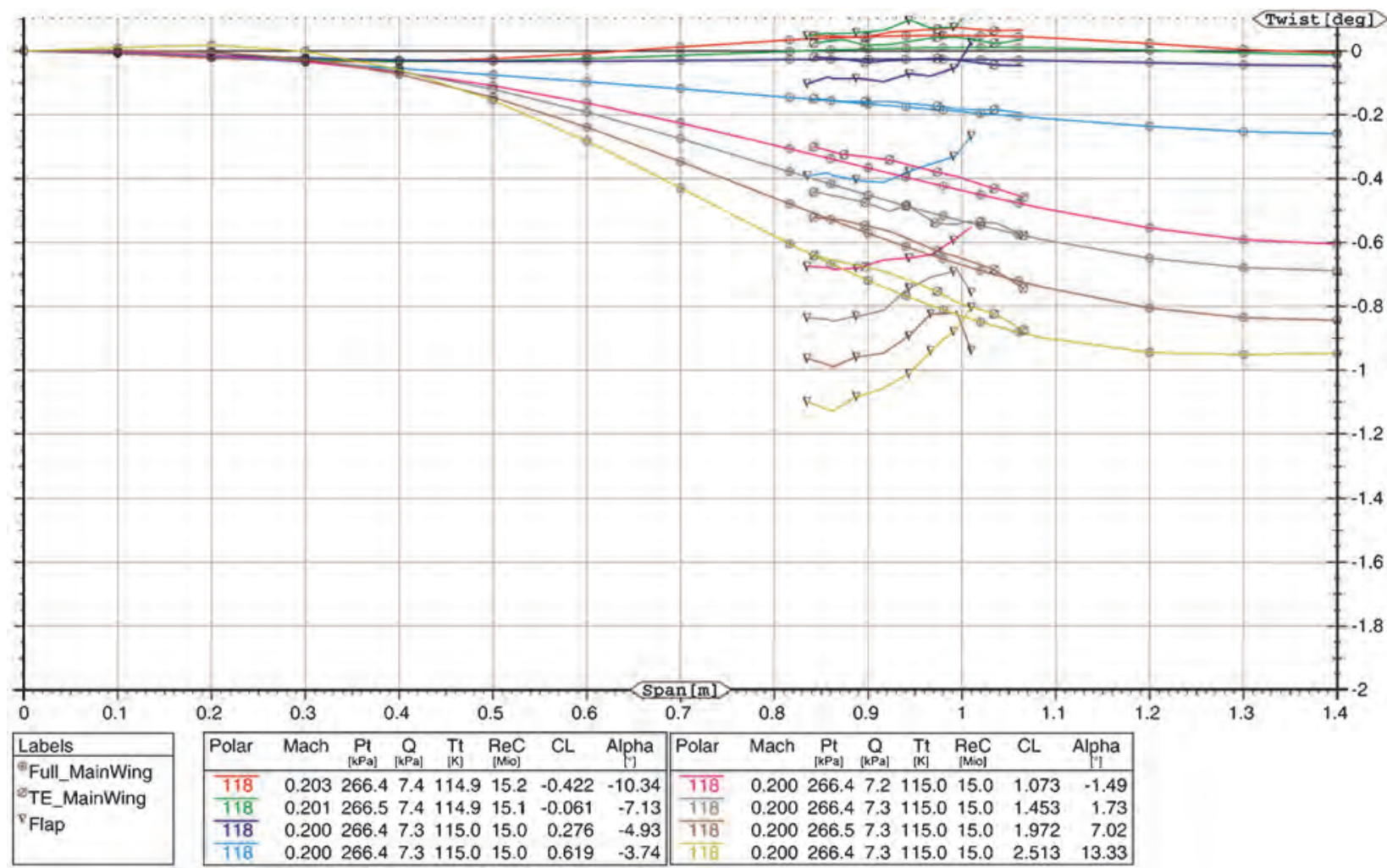

Fig. 18 Spanwise twist distribution for different lift coefficients for KH3Y complexity stage 1.

H. Reynolds Number Scaling Effects on Maximum Lift Capability of Different Complexity Levels

Figure 20 summarizes the previous results of all four configurations. Maximum lift is plotted versus the Reynolds number. With respect to a general trend in the Reynolds number dependency for all configurations, the most significant increase in the absolute values of maximum lift is found up to Reynolds numbers of $R e \sim 5 \times 10^{6}$.

In the area between $R e \sim 5 \times 10^{6}$ and $R e \sim 10 \times 10^{6}$, adverse Reynolds number effects are found for configuration stages 2 and 3 . Such effects are not observed for the configurations without nacelle

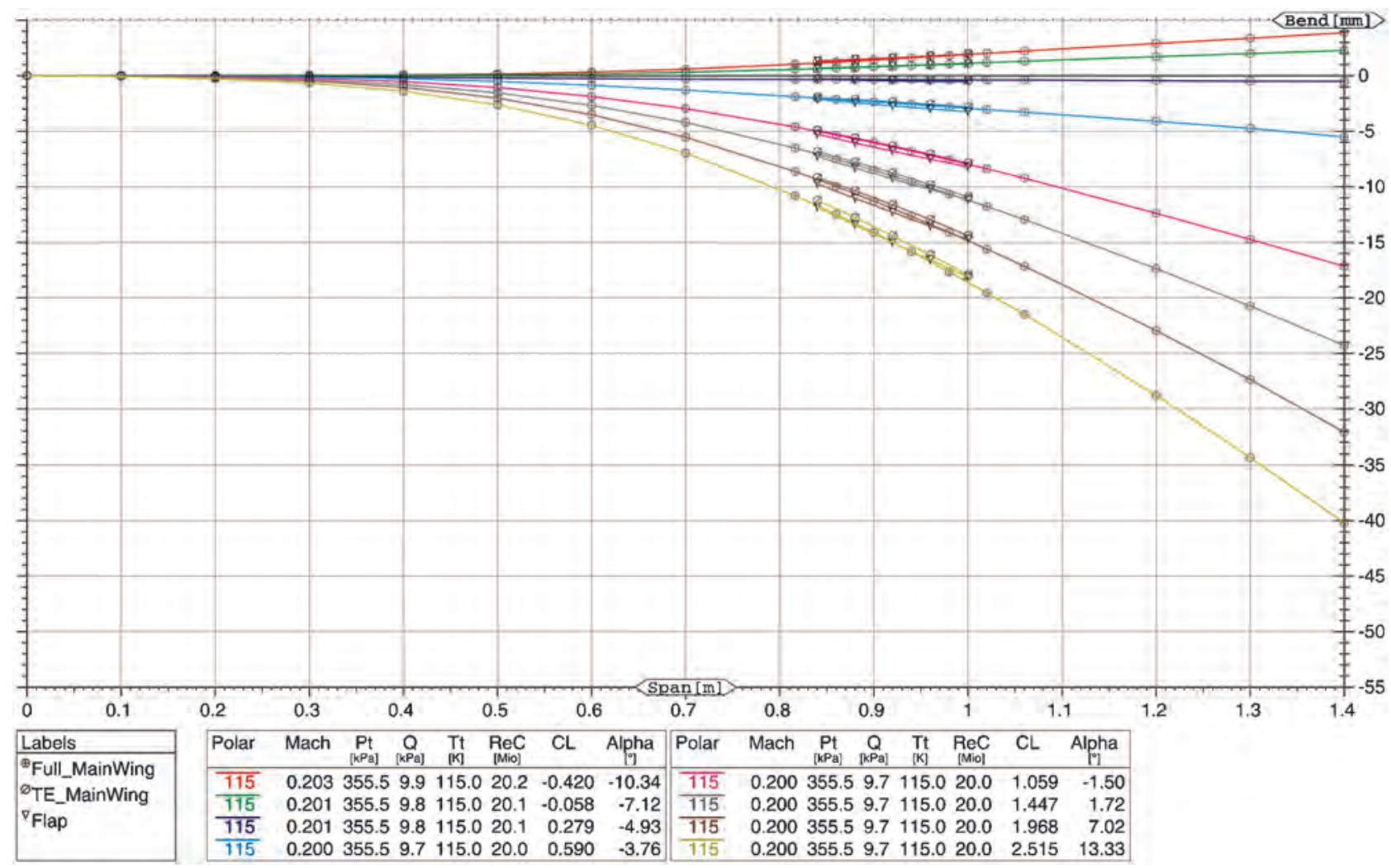

Fig. 19 Spanwise bending distribution for different lift coefficients for KH3Y complexity stage 1. 


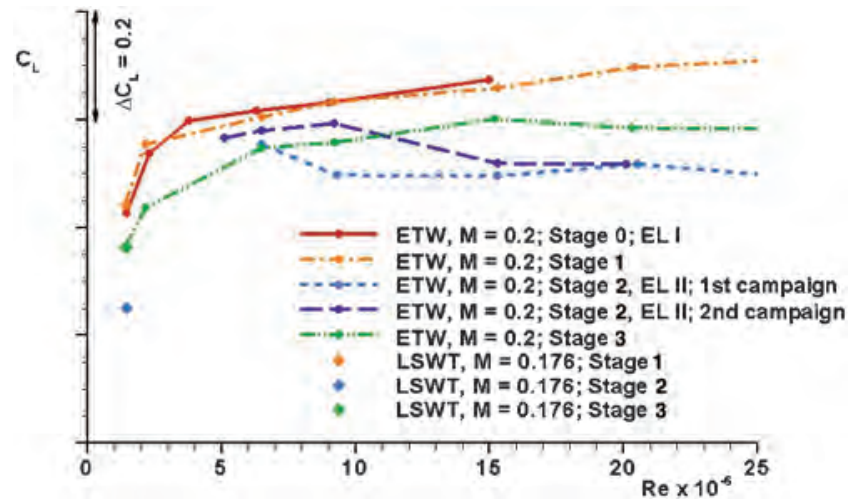

Fig. 20 Maximum lift coefficients for different Reynolds number and KH3Y complexity stages.

installation. Beyond $R e \sim 10 \times 10^{6}$, only a moderate increase in maximum lift is observed. For a Reynolds number of $R e=25 \times 10^{6}$, the maximum lift values for all three configurations appear to have leveled out. The evaluation of the atmospheric low Reynolds number results shows that the highest maximum lift value is obtained for the continuous high-lift system. The spanwise cutout at the fuselage, together with a fuselage onglet and a slat horn, reduces the maximum lift value merely by about 1 lct. The nacelle installation reduces the maximum lift for nearly 20 lcts. Installing the nacelle strake in an optimized position recovers about 12 lcts of the loss in maximum lift corresponding to $60 \%$. The increase in Reynolds number from $R e \sim 1.5 \times 10^{6}$ to $R e \sim 25 \times 10^{6}$ leads to an increase in maximum lift of $10 \%$ for configuration stage 1 and $8.5 \%$ for the most complex configuration stage 3 . For the highest Reynolds number, the lift loss due to the nacelle installation amounts to nearly $21 \mathrm{lcts}$, close to the value at atmospheric conditions. For this Reynolds number, the strake installation recovers only 8.4 lcts of this lift loss corresponding to about $40 \%$. Nevertheless, the order of the maximum lift values is maintained over the Reynolds number range. Configuration stage 2 is characterized by the strongest adverse Reynolds number effects. The repeat measurements show significant differences in the range from $R e \sim 6.5 \times 10^{6}$ to $R e \sim 15 \times 10^{6}$. Except for $R e \sim 9.3 \times 10^{6}$, these differences can be attributed to the difference in dynamic pressure between the two campaigns. This underlines the necessity for either true Reynolds number variations or a suitable way of correcting the effect of different total pressure levels. The difference for $R e \sim$ $9.3 \times 10^{6}$ needs further analysis. Interestingly, for $R e \sim 20 \times 10^{6}$, a satisfying agreement between the results of the two campaigns is observed for the same dynamic pressure level, giving an indication for the quality of the long-term repeatability.

\section{Conclusions}

A comprehensive series of experimental studies of the Reynolds number dependency of the aerodynamic forces and maximum lift on four stages of a commercial aircraft high-lift configuration with stepby-step increased complexity has been carried out. All presented results on the KH3Y wind-tunnel model refer to the landing configuration.

In general, configuration stage 1 demonstrates that carefully designed edges of the elements at the spanwise gap between slat and fuselage must not necessarily cause significant lift losses. The comparison between configuration stages 2 and 3 underlines that a nacelle strake is able to recover a considerable portion of the lift loss due to the nacelle/pylon installation.

The results show significant changes in the absolute values of maximum lift as well as in the increments due to nacelle installation and high-lift system modifications. For the present configuration, the effectiveness of the strake, optimized under low Reynolds number conditions, is considerably diminished at high Reynolds numbers representative for flight conditions. It is an open question whether this behavior can be compensated by a dedicated strake position optimization for high Reynolds numbers. Nevertheless, for the lowest Reynolds number, corresponding also to atmospheric test conditions, and the highest Reynolds number in a cryogenic high total pressure environment, the sequence of the configurations with respect to maximum lift remains unchanged.

Adverse scaling effects have been detected for the configurations with installed nacelle in the intermediate Reynolds number range. Further in-detail studies of the maximum lift determining effects and the stall behavior of the various configurations will be carried out to better understand the observed lift and drag behaviors.

The influence of variations in dynamic pressure on the maximum lift performance due to model deformation is nonnegligible for CFD validation purposes. Results of the measurement of the wing and flap deformation using the SPT/ESPT technique have shown encouraging results to quantitatively address this issue. The obtained data form a valuable basis for accompanying and future simulations of the high-lift performance using advanced numerical methods.

For a meaningful discussion of the area between $R e \sim 5 \times 10^{6}$ and $R e \sim 10 \times 10^{6}$, a detailed analysis of the stall effects appears necessary. As transition effects often play a role in this range, additional information on transition locations on the configuration is probably necessary. Providing this information in cryogenic conditions is a nontrivial task that has to be accomplished in the future.

\section{Acknowledgments}

The research work discussed in the paper was performed under the European research contract G4RD-CT-1999-00072 in the project EUROLIFT as part of the fifth framework program, and under contract AST2-2004-502896 in the project EUROLIFT II as part of the sixth framework program. The authors would like to thank the European Commission for cofunding this research activity as well as all involved EUROLIFT partners.

\section{References}

[1] Van Dam, C. P., "The Aerodynamic Design of Multi-Element High-Lift Systems for Transport Airplanes," Progress in Aerospace Sciences, Vol. 38, No. 2, 2002, pp. 101-144. doi:10.1016/S0376-0421(02)00002-7

[2] Flaig, A., and Hilbig, R., "High-Lift Design for Large Civil Aircraft," High-Lift System Aerodynamics, AGARD CP-515, 1993, pp. 31-131-12.

[3] Gault, D. E., "A Correlation of Low Speed, Airfoil Section Stalling Characteristics with Reynolds-Number and Airfoil Geometry," NACA TN 3963, 1957.

[4] Haines, A. B., "Scale Effects at High Lift and Low Speeds," Scale Effects on Aircraft and Weapon Aerodynamics, edited by A. D. Young, AGARD AG-323, 1994, pp. 27-65.

[5] Thibert, J. J., "The GARTEUR High Lift Research Programme," HighLift System Aerodynamics, AGARD CP-515, 1993, pp. 16-1-16-21.

[6] MacIntosh, W., and Wimpress, J. E., "Prediction and Analysis of the Low Speed Stall Characteristics of the Boeing 747," AGARD LS-74, 1975.

[7] Rudnik, R., and Thiede, P., "European Research on High Lift Aircraft Configurations in the EUROLIFT Projects," Council of European Aerospace Societies, 2005, pp. 16.1-16.8.

[8] Johnson, P. L., Jones, K. M., and Madson, M. D., "Experimental Investigation of a Simplified 3-D High Lift Configuration in Support of CFD Validation," AIAA Paper 2000-4217, 2000.

[9] Neitzke, K.-P., Rudnik, R., and Schröder, A., "Low Speed Validation Tests on Engine/Airframe Integration Within the EC Project EUROLIFT II," AIAA Paper 2005-3704, 2005.

[10] Seitz, A., and Kommalein, S., "DLR ETW Experiments on the F11 Configuration: Analysis and Reporting of Pressure Distributions and Force Measurements at High Reynolds Numbers," DLR Inst. of Aerodynamics and Flow Technology, EUROLIFT TR 1.3.2-8, 2003. 